\title{
CINE Y MEMORIA HISTÓRICA: LA INTERPRETACIÓN DEL PASADO RECIENTE NACIONAL EN EL CINE DE LA TRANSICIÓN ESPAÑOLA (1975- 1986) ${ }^{1}$
}

\author{
Virginia Guichot-Reina \\ Universidad de Sevilla/España \\ guichot@,us.es
}

\begin{abstract}
RESUMEN
En 1975, después de cuarenta años de dictadura, España empezó una nueva etapa en su historia: la llamada Transición democrática. Una época en donde la recién estrenada democracia tuvo que poner en funcionamiento sus reglas de juego, muy diferentes a las que se habían establecido durante el franquismo. Era necesaria una socialización política de los españoles en la cultura democrática. En este artículo se defiende la tesis de que una parte significativa del cine que se hizo en España en la Transición sirvió para generar apoyos al nuevo régimen y desprestigiar todos los no-democráticos. Nuestra muestra se compone de diez filmes españoles de dicho periodo (1975-1986) cuyo único elemento en común es el desarrollo de la acción central de la trama en el pasado reciente a su fecha de realización.
\end{abstract}

Palabras clave: Cine. Socialización política. Historia española contemporánea.

\section{CINEMA AND SOCIAL MEMORY: THE INTERPRETATION OF NATIONAL RECIENT PAST IN THE SPANISH FILMS DURING THE TRANSITION OF DEMOCRACY (1975-1986)}

\begin{abstract}
After forty years of dictatorship, with the Franco's death in 1975, Spain began a new stage in its history whose first step was called Transición democrática. Our democratic regime had to impose its own rules, extremely different to the ones previously established by Franco's regime. It was necessary a political socialization for Spanish people in the democratic culture. In this paper, our thesis is that the most of Spanish cinema during the democratic Transition was useful to generate support for the new democratic regime and to discredit all the nodemocratic one. The used sample consists of ten films filmed in the Transición democrática (1975-1986), which developed their storyline in the recent past.
\end{abstract}

Keyworlds: Cinema. Political Socialization. Contemporary Spanish History.

\section{CINEMA E MEMÓRIA HISTÓRICA: A INTERPRETAÇÃO DO PASSADO RECENTE NACIONAL NO CINEMA DA TRANSIÇÃO ESPANHOLA (1975-1986)}

\section{RESUMO}

Em 1975, após quarenta anos de ditadura, Espanha iniciou uma nova etapa na sua história: a chamada Transição democrática. Uma época onde a recém estreada democracia teve que pôr em funcionamento as suas regras de jogo, muito diferentes às que se tinham estabelecido

\footnotetext{
${ }^{1}$ Este trabajo se ha desarrollado bajo el marco del proyecto Economía, patriotismo y ciudadanía: La dimensión económica de la socialización política en los manuales escolares españoles desde el Tardofranquismo hasta la Transición (Ministerio de Economía y Competitividad, EDU2016-78143-R).
} 
durante o franquismo. Era necessária uma socialização política dos espanhóis na cultura democrática. Neste artigo defende-se a tese de que uma parte significativa do cinema que se fez em Espanha na Transição serviu para gerar apoios ao novo regime e desprestigiar todos os não-democráticos. A nossa mostra é composta por dez filmes espanhóis do dito período (1975-1986) cujo único elemento em comum é o desenvolvimento da ação central da trama no passado recente à sua data de realização.

Palavras-chave: Cinema. Socialização política. História espanhola contemporânea.

\section{CINÉMA ET MÉMOIRE HISTORIQUE : L'INTERPRÉTATION DU PASSÉ NATIONAL RÉCENT DANS LE CINÉMA DE LA TRANSITION ESPAGNOLE} (1975-1986)

\section{RÉSUMÉ}

En 1975, après la mort de Francisco Franco, et puis quarante années de dictature, 1'Espagne commence une nouvelle étape dans sa histoire appelée Transición democrática. Une époque où la démocratie naissante a dû impulser ses règles de fonctionnement, très diferentes à celles de la dictature de Franco. Il fallait une socialisation politique des espagnols pour enseigner les compétences civiques asociées à une culture démocratique. Dans cet article, on défend la suivante thèse: la plupart des films qui ont été realisés dans l'Espagne pendant la Transición democrática ont servi à générer l'appui au nouveau régime et discréditer tous ceux-là nondémocratiques. Notre échantillon s'arrange de dix films éspagnols de telle période, que nous avons étendue jusqu' à 1986, avec la fin du premier gouvernement socialiste. Tous eux développent leur trame, leur intrigue, dans le proche passé.

Mots-clés: Cinéma. La socialisation politique. Histoire espagnole contemporaine.

\section{INTRODUCCIÓN}

A la muerte del general Francisco Franco, el 20 de noviembre de 1975, se inicia en España un periodo histórico que se conoce como la Transición (democrática). Tras cuarenta años de dictadura, un horizonte nuevo se presentaba ante el pueblo español en el que se esperaba el abandono de los viejos ropajes, las normas y procedimientos típicos de regímenes autoritarios, negadores de la libertad e igualdad de derechos entre los individuos, y el avance hacia un futuro democrático para conseguir la equiparación política de España a los países occidentales vecinos. El proceso no se aventuraba fácil pues no se podía soslayar que el extinto estado franquista fue el resultado de la victoria de una sublevación militar contra el régimen legítimo republicano, en julio de 1936, que desembocó en una terrible guerra civil fratricida de tres años de duración. Además, y quizá como rasgo más aterrador, la represión hacia los vencidos se había realizado durante toda la dictadura franquista con resultados escalofriantes. Señala Carme Molinero que, actualmente, los historiadores cifran en aproximadamente ciento cincuenta mil personas las víctimas mortales de tal represión, dato 
obtenido a partir de infinidad de estudios locales que manejan fuentes diversas y complementarias. Muchas de ellas no han sido localizadas aún porque fueron enterradas en fosas comunes, campos abiertos, cunetas, etc.; de ahí que todavía en nuestros días se mantengan las reivindicaciones de muchas familias que reclaman saber dónde están sus allegados. En esta tragedia, hay que incluir, tras la Guerra Civil, alrededor de cuatrocientos mil individuos que pasaron por campos de concentración y centenares de miles de presos (MOLINERO, 2006, p. 219-246). Y no es baladí recordar que las últimas ejecuciones del franquismo se produjeron el 27 de septiembre de 1975, menos de un mes antes de la muerte de Franco, en las que murieron por fusilamiento cinco hombres, tres miembros del Frente Revolucionario Antifascista y Patriota (FRAP) y dos de Euskadi Ta Askatasuna (ETA). No, desde luego, el panorama no parecía muy alentador para un tránsito exitoso hacia un régimen democrático.

Sin embargo, la Constitución de 1978, fruto del consenso -la palabra quizá más repetida y ensalzada en estos críticos años- de las distintas fuerzas políticas vino a consagrar el advenimiento en España de una monarquía parlamentaria. Formalmente, la nación española contaba con un régimen democrático; pero, ¿había demócratas?, ¿existía cultura política democrática? Difícil haber interiorizado los valores, actitudes y procedimientos democráticos en una España en la que, hasta el momento, la clase dirigente había puesto todo su empeño en que los agentes socializadores "oficiales" (sistema educativo, medios de comunicación, sindicato vertical, asociaciones... en definitiva, todas las agencias controladas por el Estado) obstaculizasen cualquier intento de transformación en una línea democratizadora.

Era pues necesario dirigir los esfuerzos hacia la instauración de una nueva cultura política, había que socializar políticamente a los españoles de la década de los setenta para que la naciente democracia no se viniera abajo. Y para ello, había que incidir directamente en las agencias capaces de influir en los usos y costumbres del pueblo español. Como advierte acertadamente Martha C. Nussbaum (2014), todos los principios políticos precisan para su materialización y supervivencia de un apoyo emocional que les procure estabilidad a lo largo del tiempo; un soporte afectivo que tiene que ser transmitido por diversos agentes socializadores. Diferentes investigaciones muestran la intervención realizada al respecto en diferentes ámbitos, como, por ejemplo, la de Carolyn P. Boyd (2006) quien analiza el tratamiento de la Guerra Civil española en los manuales escolares de la disciplina "Historia de 
España" más usados en los centros escolares durante estos inicios democráticos ${ }^{2}$, o la de Virginia Martín Jiménez (2013) sobre el rol desempeñado por Televisión Española, que en ese momento ostentaba el monopolio de la pequeña pantalla, investigación que no deja lugar a dudas acerca de su poder de influencia en los españoles y de su utilización para servir a los intereses del nuevo gobierno encabezado por Adolfo Suárez desde $1976^{3}$.

En la línea de estos trabajos se sitúa el nuestro, que indaga sobre el papel que jugó el cine realizado en España durante la Transición en la socialización política de los españoles en la nueva cultura democrática. En otro artículo, analizamos los filmes que intentaban reflejar la realidad del momento y extraíamos como conclusión principal que se dirigían a una ciudadanía que debía interiorizar los valores esenciales de la democracia, como el respeto activo hacia los demás, la igualdad proporcionada por la común dignidad humana, la libertad en sus dos caras - libertad positiva y negativa, capacidad de autorrealización y no injerencia de los otros-, y la lucha por la justicia social. Estos valores se tenían que exteriorizar en el «saber hacer», en el uso de procedimientos acordes con el estilo de vida democrático. Manifestaciones, asambleas, citas electorales... se visualizan en los filmes, en distintos niveles y campos de actuación, desde la institución escolar (;Arriba Hazaña!, 1978) hasta el terreno político (El disputado voto del señor Cayo, 1986) como reflejo de una nueva etapa

\footnotetext{
${ }^{2}$ Boyd resalta que estos manuales compartían un compromiso común con la memoria hegemónica de dicho conflicto como una tragedia nacional, un acuerdo que respondía a las necesidades políticas de la Transición de diversas maneras. Suyas son estas palabras: "En primer lugar, los libros de texto hacen hincapié en los orígenes más que en las consecuencias de la guerra, con el objetivo de extraer lecciones políticas para el futuro; la más importante de ellas es que la incapacidad para alcanzar compromisos destruyó la República democrática y causó la Guerra Civil. Segundo, al privilegiar la memoria del fracaso democrático al mismo tiempo que silencian la del autoritarismo y la represión, dan prioridad a los valores políticos de la convivencia y estabilidad sobre los de libertad y justicia, lo que al menos a corto plazo beneficiaba el proceso de cambio democrático. Tercero, los libros de texto utilizan el tropo de las "dos Españas" para representar la guerra como la confrontación de "dos maneras de entender España" o "dos gobiernos españoles", implicando con ello una especie de equivalencia moral entre los dos "bandos". El inevitable mapa de la división del territorio nacional al inicio de la guerra sirve de marco espacial para la memoria de la nación dividida contra ella misma. El relativo silencio de los manuales sobre todo tipo de violencia política se basa en la asunción políticamente útil de que "todos fuimos culpables". Los libros de texto refuerzan así la política de "borrón y cuenta nueva" que hizo posible la transición negociada a la democracia liberal" (2006, pp. 94-95). En definitiva, la historiadora norteamericana advierte que, reflejando el compromiso con el consenso entre las élites políticas y culturales españolas, los libros de texto presentan la Guerra Civil como una lucha trágica y fratricida y guardan silencio sobre acontecimientos cuyo recuerdo podría servir para revivir los profundos desacuerdos que condujeron al conflicto armado del 1936. Este acto de olvido voluntario, como lo llama Boyd, servía de apoyo a la creación de una nueva identidad española compatible con los valores políticos centrales de la democracia, como el respeto al pluralismo.

${ }^{3}$ Indica Virginia Martín Jiménez que, a través de la televisión pública (única existente en este período) Se trataba de conseguir que la opinión pública respaldara las decisiones de los dirigentes de la Transición y formara parte también de ese compromiso de consenso y apoyo a una "reconciliación nacional". Comenta Martín: "Los dirigentes de la Transición diseñaron un plan televisivo ya que consideraban que había que lograr que los españoles apoyaran a los artífices del cambio y fueran respaldando cada una de las decisiones que se tomaran -el nombramiento de Suárez como presidente del Gobierno, Ley para la Reforma Política, la Constitución, etc.mientras que se producía una socialización en política democrática. Teniendo esto en cuenta, la televisión, como instancia socializadora y legitimadora, a la par que espacio informativo en su más amplio sentido, se convirtió en un marco de referencia para la opinión pública (2013, p. 307)
} 
(GUICHOT-REINA, 2017). En esta ocasión, nuestra investigación se centra en los filmes realizados en la Transición pero que desarrollan su acción en el pasado reciente (guerra civil y franquismo) dado que deseamos conocer qué interpretación del mismo se privilegiaba y, a su vez, qué enseñanzas cara a la socialización política de la nueva ciudadanía se pretendían ofrecer. Nuestra muestra se compone de diez películas que se realizaron entre 1975, año de la muerte del dictador, y 1986, término del primer gobierno socialista en el que historiadores como Puelles Benítez (1986) sitúan su final ${ }^{4}$. Las películas examinadas son las siguientes: Las largas vacaciones del 36 (1976, Jaime Camino), Los días del pasado (1977, Mario Camus), El corazón del bosque (1979, Manuel Gutiérrez Aragón), La Colmena (1982, Mario Camus), Demonios en el jardín (1982, Manuel Gutiérrez Aragón), El Sur (1983, Víctor Érice), Tasio (1984, Montxo Armendáriz), Los Santos Inocentes (1984, Mario Camus), y La Vaquilla (1985, Luis García Berlanga). Incluimos también La muchacha de las bragas de oro (1979, Vicente Aranda) por sus continuas referencias al pasado que nos dan oportunidad para el análisis del franquismo.

El trabajo, tras esta introducción, lo estructuramos en tres partes. En primer lugar, haremos algunas reflexiones sobre el trinomio socialización política-memoria histórica- cine. Seguidamente, procederemos al examen y comentario de las películas seleccionadas, extrayendo los resultados alcanzados vinculados al concepto de "cultura política". Por último, presentaremos algunas conclusiones en las que destacaremos los principales elementos comunes encontrados en los filmes y que contribuyeron a la consolidación de los principios democráticos recién estrenados.

\section{CINE, SOCIALIZACIÓN POLÍTICA Y MEMORIA HISTÓRICA}

La socialización política puede ser entendida como el conjunto de procesos mediante los cuales los miembros de una sociedad aprenden e interiorizan principios, normas, procedimientos y valores relevantes para su conducta como seres políticos. En la actualidad, hay numerosos estudios sobre dicha socialización, mayoritariamente desde la perspectiva de

\footnotetext{
${ }^{4}$ No hay un consenso entre los historiadores e intelectuales que han estudiado a fondo la Transición en las fechas de inicio y final de la misma. En cuanto al inicio, aunque la más utilizada es 1975, con la muerte de Franco el 20 de noviembre, se manejan otros hitos para situar el comienzo como el nombramiento como Presidente del Gobierno y asesinato por la banda terrorista ETA de Carrero Blanco en 1973 (PREGO, 1995; JULIÁ, 1996) o la dimisión de Arias Navarro como Presidente del primer gobierno de la Monarquía el 1 de julio de 1976 (MORODO, 1999). La victoria por mayoría absoluta del Partido Socialista Obrero Español (PSOE), en 1982, suele ser el acontecimiento más frecuente empleado para marcar el final de la Transición, aunque, como señalamos, hay historiadores que prefieren situarlo en 1986, cuando termina el primer mandato socialista, ya que se da muestra de una mayor consolidación de la democracia.
} 
las ciencias políticas ${ }^{5} \mathrm{y}$, sin embargo, son escasos los realizados bajo la perspectiva de la historia de la educación, campo en el que nos situamos, entendiendo "educación" en un sentido amplio, no limitada a la escolarización.

Muchos agentes contribuyen a la socialización política del individuo desde que nace: la familia, la escuela, el grupo de amistades y, por supuesto, los medios de comunicación de masas. El cine es uno de ellos, con fuerte presencia en nuestros días, y, más aún, en la época en la que centramos nuestro estudio, la comprendida entre 1975 y 1986, en la que aún no competía con el todopoderoso Internet ni con las múltiples alternativas que ofrece actualmente la televisión privada. Como agente de socialización, posee un importante componente conformador de modelos de comportamiento, a lo que se une, tal como indica Reia-Baptista, un enorme poder de atracción que se replica en otros medios de comunicación a través del uso del lenguaje cinematográfico en todo tipo de contextos: vídeos musicales para promocionar música, imágenes reales para optimizar los videojuegos; géneros cinematográficos y estrellas de cine para cubrir los objetivos de la publicidad, etc. (2012, p. 86). Esta capacidad de atracción se relaciona directamente con su capacidad para mover el mundo de nuestros sentimientos y afectos ${ }^{6}$. Los distintos elementos que conforman el filme nos «hablan», comunican, y nos transmiten —inducen- emociones: tanto el lenguaje verbal como el lenguaje no verbal, que recoge no sólo los gestos, actitudes y posturas de los distintos personajes, sino también la música, la fotografía o el montaje de las escenas. Películas que recrean un tiempo histórico determinado, como las que examinaremos a continuación, intentan provocar en el público espectador ciertas emociones hacia el suceso, situación, época, personajes, que se presentan en la pantalla.

\footnotetext{
${ }^{5}$ Los estudios sobre socialización política datan de finales de los años cincuenta del siglo XX. Las primeras investigaciones se incluían en las corrientes funcionalistas de la teoría de la acción social y de las corrientes behavioristas, hegemónicas en los estudios de psicología norteamericanos. A partir de esa fecha, las investigaciones sobre este ámbito se incrementaron dentro de los estudios políticos y se escindieron en variadas orientaciones. Todas tenían como elemento común la consideración de la naturaleza pedagógica de la socialización política, en tanto que su mecanismo principal es un proceso de aprendizaje.

${ }^{6}$ El uso común del término emoción suele englobar la idea de sentimiento. Damásio, neurólogo portugués de reputado prestigio, los va a separar tal como expresa en la siguiente metáfora: "Las emociones se representan en el teatro del cuerpo. Los sentimientos se representan en el teatro de la mente". Las emociones "son acciones o movimientos, muchos de ellos públicos, visibles para los demás pues se producen en la cara, en la voz, en conductas específicas. (...). Los sentimientos siempre están escondidos, como ocurre necesariamente con todas las imágenes mentales, invisibles a todos los que no sean su legítimo dueño, pues son la propiedad más privada del organismo en cuyo cerebro tienen lugar" (DAMÁSIO, 2005, p.32). Las emociones están formadas por reacciones simples que promueven la supervivencia del organismo. Todos los seres vivos nacen con mecanismos para resolver automáticamente los problemas básicos de la vida, buscan bienestar. Los dispositivos emocionales se activan al nacer, con poca o ninguna dependencia del aprendizaje, pero a medida que la vida continúa, éste desempeñará un papel importante a la hora de determinar cuándo se van a desplegar los dispositivos. Los sentimientos son la expresión mental de cómo nos percibimos corporalmente.
} 
Esta inducción de emociones y sentimientos mediante el visionado de las producciones cinematográficas, conducentes a que las ideas y pensamientos asociados a los mismos queden más afianzados en nuestras estructuras cognitivas, es fundamental en el terreno de la socialización política. Referíamos en la introducción que Martha C. Nussbaum ha sido una de las filósofas contemporáneas que más se ha interesado por este tema, como se advierte en su extenso libro Political Emotions: Why love matters for justice. Allí defiende que hay emociones que podemos denominar «públicas», sobre el espacio político en que se vive, y que se relacionan con los principios políticos, los objetivos del Estado, las instituciones y sus dirigentes, la percepción de los conciudadanos como habitantes con los que se comparte un contexto público común, etc. Tales emociones traen consecuencias para el progreso de las sociedades en la consecución de sus metas: "Pueden imprimir a la lucha por alcanzar esos objetivos un vigor y una hondura nuevos, pero también pueden hacer descarrilar esa lucha, introduciendo o reforzando divisiones, jerarquías y formas diversas de desatención o cerrilidad (2014, p. 14 y 15). Si, como defiende la tesis principal de Nussbaum, todos los principios políticos necesitan para su materialización y su supervivencia de un apoyo emocional que les dote de estabilidad a lo largo del tiempo, entonces podríamos mantener como hipótesis de partida que el cine realizado en la Transición contribuyó a transmitir y reforzar los valores, actitudes, comportamientos, conocimientos... vinculados al nuevo régimen democrático ${ }^{7}$.

La idea del cine como agente de socialización política podemos ligarla con el concepto de memoria colectiva, esencial para comprender cómo se configuran las identidades socio-políticas de la ciudadanía. Siguiendo a Boyd, podemos definir la memoria -todavía sin adjetivos añadidos-, como "el proceso mediante el cual los sujetos construyen relatos personales capaces de sustentar identidades que sean a la vez íntegras y eficaces" (2006, p. 79). Sin ella, sin esa conciencia del pasado, los seres humanos no podemos dar sentido a nuestra existencia ni planificar un futuro de manera razonable. Siendo nuestra memoria selectiva -no todo pasa a ser recordado- y subjetiva -se basa en la interpretación personal de una realidad-, la utilizamos para transformar nuestra experiencia recordada en historias comprensibles en las que los hechos pasados condicionan nuestro presente y proporcionan asideros para planificar la acción futura. En un sentido estricto, recordar es un proceso psicológico que únicamente ocurre en mentes individuales y encierra sólo los acontecimientos

\footnotetext{
${ }^{7}$ Entre los trabajos empíricos que analizan la relación entre socialización política y cine cabe destacar, por coincidir en el periodo histórico objeto de nuestra investigación, el artículo de Natalia Ardánaz, "La Transición política española en el cine (1973-1982)”, de 1998.
} 
que han sido experimentados directamente. Sin embargo, tiene también sentido hablar de memoria colectiva o social, que se representa y transmite a través de prácticas culturales simbólicas o mnemotécnicas que dan forma y sustentan las identidades colectivas.

De acuerdo con Aguilar (1996), la memoria colectiva "consta del recuerdo que tiene una comunidad de su propia historia, así como de las lecciones y aprendizajes que, más o menos conscientemente, extrae de la misma" (p. 25). Comprende tanto el contenido recuerdos de determinados sucesos históricos- como los valores relacionados con su evocación -lecciones y aprendizajes históricos-, modificados, habitualmente, por el presente. Es esencial tener en cuenta esta última idea, como señala el conocido como presentismo historiográfico, integrado por autores de la talla de Halbwachs, Lummis, Hobsbawm o Nerone. Lummis (1987) sostiene que la memoria popular es la imagen colectiva y generalizada del pasado que, si bien apoyada por la sociedad, no procede de ella. Este recuerdo común está potentemente influenciado y ajustado por las instituciones con poder económico, político y social del presente, y éstas refuerzan la difusión y popularización de determinadas imágenes del pasado a expensas de otras mediante los medios de comunicación social. De ahí que Lowenthal (1985) afirme que el pasado es creación nuestra, en cuanto a que constituye una imagen siempre cambiante y en continua reinterpretación según las necesidades del momento.

La memoria colectiva es selectiva al igual que la individual: no contiene todos los acontecimientos pasados de la comunidad. En cada período, hay momentos históricos que, por su especial pertinencia para el momento actual, se vuelven más importantes y más susceptibles de influir en la realidad coyuntural de esa época. Coincidimos con Aguilar (1996, pp. 35-36) en que no “cualquier" pasado es relevante en "cualquier" presente y, en ese sentido, la memoria histórica de un país es aquella parte del pasado que, debido a unas circunstancias sociales, políticas y económicas concretas, posee capacidad de influir sobre el presente, tanto en sentido positivo -como ejemplo a imitar-, como negativo -situación que hay que evitar-.

Dadas las reflexiones anteriores, se entiende la enorme fuerza potencial que tiene el cine, cuando es visto por miles de espectadores, como creador de memoria histórica. A través de la interpretación del director/a cinematográfico/a, en el caso de los filmes que se sitúan en el pasado de los espectadores, se realiza una reconstrucción del mismo desde el presente, que modula, recrea, olvida y da significado, de diversos modos, a dicha realidad pretérita. Además, una generalización de la atención al pasado más reciente en las producciones cinematográficas de la Transición que recrean situaciones pretéritas nos habla de que 
directores y productoras consideraron éste especialmente relevante para el momento político en que se vivía. Adelantamos ya, respondiendo a Aguilar, que en este caso aparecerá más como contraejemplo, como situación repulsiva o rechazable, que como modelo a seguir.

\section{EL PASADO RECIENTE DESDE EL CINE DE LA TRANSICIÓN: UN ALEGATO CONTRA AUTORITARISMOS Y NEGACIÓN DE LIBERTADES}

Expuesto el marco teórico en el que vamos a situar nuestro análisis, pasamos a efectuar un examen desde el punto de vista de la socialización política de diez filmes que, por orden de producción, son los siguientes: Las largas vacaciones del 36 (1976, Jaime Camino), Los días del pasado (1977, Mario Camus), El corazón del bosque (1979, Manuel Gutiérrez Aragón), La muchacha de las bragas de oro (1979, Vicente Aranda), La Colmena (1982, Mario Camus), Demonios en el jardín (1982, Manuel Gutiérrez Aragón), El Sur (1983, Víctor Érice), Tasio (1984, Montxo Armendáriz), Los Santos Inocentes (1984, Mario Camus), y La Vaquilla (1985, Luis García Berlanga). Sitúan su acción durante el período de Guerra Civil y Franquismo. El filme La muchacha de las bragas de oro transcurre en la Transición, pero hace referencias constantes a la dictadura franquista.

Antes de comenzar, queremos destacar un hecho evidente: la multiplicidad de interpretaciones que admite un mismo texto, en este caso, una película. Cada sujeto procesa la información de una forma distinta, incidiendo en ello múltiples variables. Además, hemos de añadir que todos somos "hijos de nuestro tiempo", y, sin lugar a dudas, el visionado de estas películas a comienzos del Tercer Milenio adquiere significados diferentes a los del momento en que se realizaron. Sin embargo, éste es un hecho intrínseco al oficio de historiador; de ahí que hayamos acudido a distintos recursos para procurar que los resultados presentados ofrezcan verosimilitud y fiabilidad —entrevistas que fueron concedidas por los directores sobre sus películas, análisis del contenido de los guiones, monografias y artículos sobre el período, etc. ${ }^{8}$

Empezaremos nuestro análisis por las dos películas que hacen referencia a la Guerra Civil: Las largas vacaciones del 36 y La vaquilla. La primera es una película de Jaime Camino que se empezó a rodar antes de la muerte del dictador Franco y se terminó una vez fallecido. Se estrenó en julio del año siguiente, 1976, tratando nada menos que el tema de la

\footnotetext{
${ }^{8}$ No hemos realizado entrevistas a una muestra significativa de personas que hubieran visto las películas utilizadas en esta investigación en los años de Transición. Se les podría haber preguntado sobre las emociones que les suscitaron y su influencia (si creían que la hubo) en su comportamiento ciudadano. En todo caso, siempre estaríamos utilizando la memoria de los sujetos de la muestra que, como sabemos, dista mucho de tener un $100 \%$ de fiabilidad. Somos conscientes que dichas entrevistas hubieran enriquecido nuestro trabajo.
} 
guerra civil española (1936-1939) en unos momentos claramente delicados en el panorama político de España, pues acababa de dimitir, forzado por el Rey Juan Carlos I, Carlos Arias Navarro como Presidente del Gobierno (cargo que ya ostentaba antes de morir el general Francisco Franco), siendo sustituido por Adolfo Suárez, un joven político que provenía del Movimiento Nacional y había sido escogido por el monarca para que dirigiera la Transición bajo la tutela de la Corona. Entre la mayoría de los españoles existía una gran incertidumbre acerca del futuro político que esperaba a la nación porque aún no estaba nada claro el avance hacia un régimen democrático ${ }^{9}$. A nuestro parecer, este elemento es esencial para comprender el estilo de neutralidad, de buscada "objetividad" de la película. El filme comienza el 19 de julio de 1936 y se sitúa en un pueblecito cercano a Barcelona donde pasan sus vacaciones estivales varias familias de la burguesía media. Lo que iban a ser unas semanas de relajación antes de que los niños y adolescentes comenzaran el curso académico y se retornara a la rutina laboral se convierte en "un largo verano", en una reclusión voluntaria de casi tres años (hasta la finalización de la contienda) en un lugar con menos probabilidad de sufrir bombardeos que Barcelona capital. A través de esta película coral, se intenta reflejar, casi como si de una España en miniatura se tratase, las vivencias de la guerra por parte de la sociedad civil enmarcadas en el proceso que va desde el inicio hasta el fin del conflicto bélico: separación y muerte (en algunos casos) de seres queridos; temor por la propia vida; carencia de bienes básicos, como el alimento; en definitiva, un clima de inseguridad y desazón. Sin embargo, hay dos aspectos, relacionados entre sí, que, a nuestro entender, el director quiso subrayar especialmente mediante la narración de la historia: a) en uno y otro bando, el republicano y el nacional, se cometieron tropelías; al abrazo de una y otra ideología, hay gente buena y gente mala; b) la guerra es siempre una pérdida para todos.

Para avalar estas conclusiones, propondremos varios ejemplos. Al comienzo de la película, se observa como el cura, el sacristán y tres personas más se atrincheran en la iglesia del pueblo cuando se enteran del golpe militar contra el régimen republicano, y disparan contra un grupo numeroso de gente del pueblo, también armada, con el alcalde al frente, que se deduce que son de izquierdas. El alcalde les conmina a que se entreguen y tiren las armas, prometiéndoles que se les hará justicia, pero, al mismo tiempo, se observa el desenfreno de una parte de la masa popular que quiere automáticamente fusilarlos. Asimismo, en otra

\footnotetext{
${ }^{9}$ A pesar de que en el discurso de su proclamación como Rey de España el 22 de noviembre de 1975, Juan Carlos I anunciara que comenzaba una nueva etapa en la historia de España, sus palabras no fueron acompañadas de una alteración en la presidencia del Gobierno ya que fue confirmado en su cargo Arias Navarro (último Presidente del Gobierno designado por Franco). Durante los meses que duró su presidencia, la idea extendida era que el sistema político español era un "franquismo sin Franco".
} 
escena, miembros de la CNT, sindicato anarquista, se desplazan en un coche a la casa del dueño de una fábrica del pueblo y por lo que se escucha se advierte que, al menos alguno de ellos, quiere ante todo vengarse de él por el despido de determinado obrero. Frente a estos desatinos de una parte de los rojos (como se denominaba a aquellos que abrazaban doctrinas izquierdistas), el ejemplo de honradez, de integridad moral y profesional, del maestro del pueblo, interpretado por el actor Paco Rabal que, ante la cara preocupada de uno de los niños ricos (a los que termina dando clase por petición de las familias burguesas) por su confesión de ser "rojo" declara: "Imagino lo que dice tu padre: Que los rojos son malos, que queman las iglesias, que pillan, roban y asesinan. Pues mira, Pedrito, yo también soy rojo y ni robo ni asesino. Me dedico simplemente a enseñar geografía, historia, matemáticas, lengua y literatura para desasnar a los niños de este pueblo y ahora a vosotros". De este modo, el director busca romper con maniqueísmos conectados a ideologías, los buenos versus los malos, y eliminar asimismo ciertos estereotipos ${ }^{10}$, un posicionamiento distanciado de las que habían sido las consignas oficiales en todo el franquismo.

La otra película sobre el conflicto fratricida analizada es La Vaquilla, dirigida por Luis García Berlanga una década después que la anterior, en 1985, situándose la acción en plena guerra civil española, tras dos años de contienda ${ }^{11}$. Fue la primera comedia que se hizo sobre dicho conflicto y obtuvo un ingente número de espectadores tanto en su año de estreno como en los posteriores hasta la actualidad en sus emisiones por la pequeña pantalla ${ }^{12}$. El género de la comedia en el campo de la socialización política es especialmente valioso, tal como defiende Nussbaum al recordar el valor que tenía para el ciudadano ateniense de la Grecia clásica. El papel de los festivales, tanto cuando se representaban tragedias como

\footnotetext{
${ }^{10}$ En este sentido, por ejemplo, es curioso que el único militar que adquiere cierta relevancia en el filme es Vicente Parra, que hace de capitán del ejército republicano y morirá en el frente defendiendo al régimen legítimo democrático. Para los españoles de la Transición, acabados de salir de la dictadura del general Franco, casi se establecía una equivalencia entre ejército y franquismo, por el apoyo masivo y decisivo que le proporcionó el estamento militar. Hablamos de ruptura de estereotipos porque en este caso, como se aprecia, se produce una ruptura de la equivalencia.

${ }^{11}$ Según el crítico de cine Augusto M. Torres, tanto Rafael Azcona como Luis García Berlanga empezaron el guión de la película a mediados de los sesenta del siglo XX. El filme, debido a la prohibición de la censura franquista, no pudo hacerse entonces. Dice el crítico que el guión contenía "el mensaje, revolucionario para el momento, de que entre los sublevados y los republicanos destrozaron España” (TORRES, 1999, pp. 855-856)

${ }^{12}$ Aguilar comenta que dicha película, con algo más de 1.900 .000 espectadores acumulados, ocupa el puesto noventa de las cien películas españolas con más público de la historia (2006, p. 289). Aguilar toma como fuente el anuario del Boletín Informativo del Control de Taquilla, publicado por el Ministerio de Educación, Cultura y Deporte, de 2002, contrastando los datos con los que se daban en la página web del Ministerio de Cultura a 31 de julio de 2004: http://cultura.mecd.es/cine/index.jsp. Ofreciendo datos más recientes, queremos destacar que la última vez que tenemos constancia que se repuso en televisión fue en julio de 2016, en un programa de una cadena pública titulado "Historia de nuestro cine" y gracias a ella logró su récord histórico de audiencia $(6,9 \%$ de cuota de pantalla en La 2, cadena pública), obteniendo casi un millón de espectadores (938000). Vd. en $<$ http://www.audiovisual451.com/la-vaquilla-otorga-a-historia-de-nuestro-cine-de-la-2-su-mejor-dato-deaudiencia/>, consulta el 9 de marzo de 2017.
} 
cuando se escenificaban comedias, era formar a la ciudadanía. Las actuaciones eran momentos de honda emotividad y esas emociones eran valoradas como aportaciones importantes al debate político. La tragedia -señala Nussbaum- tiene el poder de incidir en nuestra fragilidad física y fomenta una compasión que vence las tendencias a la arrogante negación de nuestra humanidad más básica. La comedia, como la de Aristófanes, con sus insistentes referencias francas y alegres a las funciones fisiológicas, reclama a todos los espectadores que se deleiten en su propia naturaleza física y tendría una función similar. Mientras que las tragedias poseían como rol principal dirigir la atención emocional e imaginativa hacia los derechos fundamentales y hacia el daño que se ocasiona si esos derechos no están presentes -si se reflexiona adecuadamente sobre ellos y se siguen sus consecuencias lógicas hasta el final, esos dilemas influyen en la compasión y solucionan algunos errores más probables de esta-, la comedia de Aristófanes, con sus insistentes referencias francas y alegres a las funciones fisiológicas, pide a todos los espectadores que se complazcan en su peculiar naturaleza física. Y subraya Nussbaum:

\footnotetext{
El espíritu que animaba, no ya al teatro de Aristófanes, sino a los festivales cómicos en general, era el de la defensa de la paz pues se entendía que sólo en paz podemos disfrutar de la comida, la bebida y el sexo (e incluso del pedorrearse o del cagar). [...] Así pues, los festivales cómicos como los trágicos, trataban asuntos dolorosos: los límites del cuerpo, su sometimiento natural a indignidades, su cercanía a la muerte. Pero el espíritu de la comedia [...] convierta esas desmoralizadoras condiciones en fuentes de deleite (2014, p. 329).
}

Y esta es una función, la de la defensa de la paz como medio de poder disfrutar de los pequeños placeres de la vida, la que resalta La vaquilla de Berlanga. La situación de entrada se presenta absolutamente esperpéntica: estamos en un frente de trincheras y allí no se dispara ni un tiro, sino que los soldados dormitan, juegan, escriben cartas... e incluso, para poder fumar, soldados del bando nacional y del bando republicano intercambian los materiales necesarios (en una zona tienen el tabaco; en otra, el papel de fumar). Durante el filme se aprecia que los reclutas, en general, no están combatiendo por la defensa de unos principios ideológicos con los que se sientan comprometidos moralmente, sino que el azar hizo que en el momento de la contienda estuvieran en una zona u otra (republicana-nacional) $\mathrm{y}$ es lo que dio lugar a que combatiesen bajo una u otra bandera. Tal como escribe Aguilar, $L a$ vaquilla "nos ofrece una imagen ingenua, amable y desideologizada de los combatientes de ambos bandos, donde lo importante es su dimensión humana, sus comunes miedos y apetencias, y su incomprensión, también compartida, de los motivos por los que están luchando" (2006, p. 378). El deseo de todos radica principalmente en poder disfrutar de una vida tranquila y pacífica. 
La historia cómica gira en torno a la idea por parte de los republicanos de raptar a la vaquilla que iba a torearse en un festival que se organiza en un pueblo tomado por los nacionales para lograr desmoralizarlos y asimismo poder procurarse algo de sustento, porque escasean los víveres. El plan es que un equipo formado por cinco hombres del bando republicano, guiados por uno de ellos, oriundo de la zona, lleguen al pueblo aprovechando la noche y rapten al animal, pero todo se va complicando hasta tal punto que al final terminan incluso participando, haciéndose pasar por nacionales, en la procesión de la Virgen. Todas las peripecias están teñidas de "lo humano, demasiado humano" como son esas pequeñas cosas de la vida que a la mayoría de los mortales nos proporcionan felicidad: el estar con nuestros seres queridos -el guía desvía a todos sus compañeros del establo donde está la vaquilla para poder así ver la finca que iba a heredar su novia-, el disfrute del sexo -la cuadrilla republicana intenta aprovechar su paso por un pueblo para gozar de los servicios de unas prostitutas tras meses de abstinencia por culpa de la guerra-, las comilonas -no tienen reparos, disfrazados de nacionales, en aprovechar un convite que da uno de sus enemigos, el marqués-, etc. Y constantemente, hay alusiones a que percibamos las semejanzas de todos los seres humanos (relacionadas fundamentalmente con el hecho de que todos tenemos un cuerpo con necesidades) y el, en ese sentido, despropósito de las contiendas (mucho más de las civiles). Así, por ejemplo, cuando los cinco republicanos se bañan desnudos en un arroyo y aparecen unos soldados nacionales que los confunden con otros de su mismo bando, comenta uno de los republicanos: "Lo que es la vida. Aquí en pelotas, ni enemigo ni nadie"; en el prostíbulo, también coinciden hombres de toda especie y condición, y el "arrimarse" a las mujeres tampoco parece hacer distingos por ideologías.

La comedia, por tanto, y en este caso, La vaquilla, es una forma de darnos cuenta de nuestra fragilidad humana, una manera de hacernos ver la importancia de la paz para disfrutar de los placeres y aprovechar esta vida que nos ha sido dada y que no tiene repuesto. Nos anima a reírnos de nosotros mismos, y a darnos cuenta de cuáles deben ser las prioridades de nuestra existencia, entre las que no debe estar la discordia con los otros, seres tan frágiles como nosotros mismos y con semejantes necesidades. Además, hay otro aspecto que ha de destacarse con respecto a la risa: desempeña la función crucial de exorcizar el miedo y permite acercarnos a realidades "prohibidas", en este caso, a una época de la historia que durante mucho tiempo, para los españoles, constituyó un tabú (BERTHIER, 2003, p. 166167). Creemos que es a ello, en cierta medida, a lo que se refiere Teresa Vilarós, cuando dice que La vaquilla nos presenta una guerra civil “domesticada" (1998, p. 240): por una parte, la 
hacemos "tratable", aprendemos a convivir con ella; y por otra, controlamos o dominamos el miedo que desencadena el horror del conflicto ${ }^{13}$.

Con Los días del pasado, película de 1977 dirigida por Mario Camus, y El corazón del bosque, de 1979 con dirección de Manuel Gutiérrez Aragón, entramos en la representación del papel que jugó en la posguerra el fenómeno del "maquis". Su origen se encuentra en los contingentes humanos de ideología de izquierda que, frente al avance de las tropas franquistas, se esconden en los montes para evitar las duras represalias y deciden continuar con su lucha antifascista incluso tras la victoria del bando nacional acaudillado por Franco. Mientras que en la primera, situada en 1945, la historia de amor entre Juana (la actriz Pepa Flores, Marisol), una maestra andaluza que pide traslado al Norte del país con la esperanza de encontrarse con su novio Antonio (su entonces pareja en la vida real, Antonio Gades), un maquis escondido en las montañas junto con un grupo de camaradas, cobra el principal protagonismo; en la segunda, localizada en 1952, la trama central gira en torno a la vida de los maquis a través de la figura de "El Andarín" y a la dura represión sufrida, así como a la referencia a que el propio partido comunista se encargó en determinado momento de desmantelar estas guerrillas, incluso en ocasiones llegando al asesinato ${ }^{14}$.

En cuanto al tema que nos ocupa, los mensajes dirigido a la socialización política de los españoles, espectadores de la película, el primer filme transmite una idea de la posguerra como una etapa sórdida, oscurantista, llena de miseria y privaciones. Sensaciones que induce, de entrada, la escasa luminosidad de la mayor parte de las escenas del filme, rodadas en invierno, en días desapacibles, grises y lluviosos en el Norte peninsular ${ }^{15}$, que sólo se rompe cuando al final del relato la maestra se va sola al Sur, en donde el sol luce y el cielo aparece con un celeste radiante, quizá como una metáfora de la necesidad de emprender una nueva vida. Y que se refuerzan con la visión de la escasez de la vivienda de la maestra, que habita en un triste cuartucho donde hace tanto frío que tiene que dormir incluso poniéndose encima del camisón una rebeca; con la imagen de la escuela, vieja, destartalada y con muy pocos recursos y materiales escolares; y con la reproducción de interiores de algunas casas del pueblo, en las que no existe ningún lujo ni acomodo. Sin embargo, si importante son estas privaciones, habrá una que destaca por encima de todas: la de libertad, que aparece como el bien más preciado, como el recurso imprescindible para ser feliz, para gozar de la vida, como queda

\footnotetext{
${ }^{13}$ Por supuesto, hay otras interpretaciones sobre el mensaje central de la película. Aguilar (2006, p. 289) cree que lo que claramente prima en la cinta es el mensaje de culpabilidad colectiva por las brutalidades cometidas durante la contienda, que es precisamente el acuerdo sobre el que se asienta la Transición.

${ }^{14}$ Cfr. el libro de José Javier Esparza El libro negro de Carrillo (Editorial Libros Libres, Madrid, 2010).

${ }^{15}$ La película fue rodada en Bárcena Mayor y Comillas.
} 
reflejado cuando Juana, en uno de sus encuentros clandestinos con Antonio, le pide que se marchen a Francia, y ante la pregunta de éste sobre el motivo (“¿A qué”), le responde ella con decisión: “A vivir”. A poder vivir realmente, añadiríamos nosotros.

En El corazón del bosque se ve de manera aún más cruda y terrorífica las persecuciones a los maquis y la terrible dureza de la vida que éstos se han visto obligados a llevar. La Guardia Civil aparece como un órgano brutalmente represor en varias escenas de la película, como en una en la que varios guardias civiles acompañados por algunos frailes armados con escopetas ${ }^{16}$ irrumpen en una casa de monte donde vive un ex-maquis con su mujer y su hija, le sacan de allí y, sin ningún tipo de juicio, lo fusilan a pocos metros de su hogar; en otra en la que se ve a los guardias junto a una carreta con diversos cadáveres, que son de maquis o "huidos", atravesando parajes de montaña; o cuando el único maquis superviviente, aparte de El Andarín, cuenta a Juan, un miembro del Partido Comunista que había regresado desde Francia al pueblo con la misión de desmantelar estos grupos guerrilleros, que los guardias civiles habían asesinado al resto de compañeros cuando éstos habían decidido abandonar la vida de maquis y bajaban del monte de regreso a sus hogares. Como apuntábamos más arriba, el papel de Juan, afiliado al Partido Comunista, también es execrable: mata a El Andarín porque éste se niega a obedecer las órdenes del Partido de abandonar su situación de maquis. Al igual que en la película anterior, el ambiente de violencia, de falta de libertad, de temor a delaciones por parte de los vecinos, lleva al espectador a crear una sensación de repulsión hacia el momento histórico que refleja y un deseo de no volver a caer en alguno parecido. Asimismo, se observa crueldad y maldad tanto en representantes del bando nacional victorioso, ejemplificado como hemos visto por la guardia civil, al servicio del mismo, como en miembros del ala más radical de las izquierdas, ilustrada por el comunista Juan.

Otras dos películas de la muestra analizada que se sitúan en el período franquista y concretamente en la postguerra, son adaptaciones de novelas previas: La colmena y El sur. La primera se basa en el libro de idéntico título de Camilo José Cela, publicado en Buenos Aires en 1951, y cuatro años después en España, tras recibir primeramente censura; la segunda, se inspira en el relato del mismo nombre, publicado en 1985, por Adelaida García Morales. La colmena se localiza en el Madrid inmediato a la finalización de la guerra civil y es un retrato magnífico de la sociedad del momento. A través de pinceladas de la vida de los personajes quedan patente los trágicos efectos de esta lucha fratricida: la policía parando en la calle a

\footnotetext{
${ }^{16}$ Nótese aquí la alusión a la connivencia de la Iglesia Católica española con el régimen franquista.
} 
cualquier persona que se le antojase para pedirle la documentación y comprobar que "todo está en regla", sin dar ningún tipo de justificación, en un clima de miedo y temor al encarcelamiento únicamente por la potencial sospecha de simpatizar con el pensamiento de izquierda $^{17}$; la expulsión de la profesión de muchas personas por los expedientes de depuración ${ }^{18}$; la supervivencia frente al hambre generalizada a través del estraperlo o de prestación de servicios sexuales en el caso de las mujeres; la doble moral de los "hombres de bien" y reconocidos católicos practicantes, ya que muchos de ellos acuden con asiduidad a los prostíbulos o mantienen a su querida de turno; la represión sexual que empuja a que los novios tengan que acudir a una casa de citas para tratarse con cierta intimidad; la constante propaganda del Nuevo Régimen en la radio, medio de comunicación social más consumido por la clase popular, dado el extendido analfabetismo; la reprobación social de la homosexualidad (“el maricón”) considerando que es una condición anti-natural, etc. El visionado de esta película, en general rodada con muy poca luminosidad (como metáfora de la época a la que representa), transmite al público espectador el mensaje de la necesidad de no volver nunca a una situación así, de hambre, de miseria, de miedo, de oscuridad... y de la urgencia, del deber, de poner los medios para evitar caer en ella ${ }^{19}$.

El Sur es una película intimista en la que una niña, Estrella, que siente fascinación por su padre, el médico y zahorí Agustín Arenas, intenta comprender qué empujó a su progenitor al suicidio (hecho del que parte la película aunque no se descubre del todo hasta más tarde). Mediante la reconstrucción de acontecimientos de su vida junto a su padre, quizá lo más llamativo para el propósito de este trabajo es la constatación de las consecuencias que tuvo la guerra civil para España y para muchos hogares: los odios y tensiones entre miembros de una misma familia por motivos ideológicos, que les llevaron a luchar en bandos diferentes; las separaciones forzadas entre personas con fuertes lazos afectivos; la cultura del miedo, que

\footnotetext{
17 La dueña del café donde se desarrolla gran parte de la película amenaza constantemente a sus propios camareros con una posible denuncia por "rojos" (simpatizantes de las izquierdas). Cuando un camarero cae una bandeja, ella grita: "Bestia, que lo que eres es un bestia y un rojo. La culpa la tengo yo por no denunciaros a todos".

${ }^{18}$ Depuración de aquellas personas de las que se sospechase que no habían tenido una plena adhesión al Movimiento Nacional, es decir, a los ideales del régimen franquista.

19 Esta reflexión sobre las consecuencias de ciertas acciones señala Nussbaum que era una función muy importancia en los festivales trágicos de la Grecia clásica que pretendían ser un campo de primer orden de educación para la ciudadanía. Dice Nussbaum: "Los dilemas trágicos no son simplemente ocasiones para las cavilaciones de la persona implicada; son también ocasiones para la deliberación pública, es decir, momentos que invitan a los ciudadanos, espectadores trágicos, a tratar de hacerse la mejor idea posible de una situación que podría tener amplias repercusiones públicas. Hay otra vía por la que la pregunta trágica aporta esclarecimiento. Cuando somos testigos de una colisión trágica entre valores importantes, nos preguntamos lógicamente cómo han llegado las cosas hasta ese punto y si una mejor planificación previa habría podido evitar la tragedia" (2014, p. 325).
} 
provocó cubrir con un manto de silencio duras situaciones personales, ese mensaje interiorizado en la conciencia de los españoles de entonces de que "de la guerra no se habla" que aún se sigue arrastrando en nuestros días en algunos hogares ${ }^{20}$. En este caso, quizá sean dos las principales lecciones del filme desde el punto de vista de la socialización política: la importancia de intentar no llegar a una situación parecida a la de la guerra y la postguerra, que ya hemos constatado en otras películas analizadas; y la de rescatar el pasado como mecanismo para comprender mejor nuestro presente, la necesidad de reconstruir la historia, de recuperar la memoria.

Demonios en el jardín, filme de 1982, se localiza también en el período de posguerra. Su director, Manuel Gutiérrez Aragón, nacido en Torrelavega en 1942 en una familia conservadora de raíces cubanas, siempre mantuvo respecto a esta película que, con ella, trataba de contar su infancia. En efecto, el retrato de familia que se ve reflejado en la pantalla se construye a través de los ojos de un niño que, desde su lecho de enfermo, no se sabe muy bien si imaginario, condiciona la vida de su alrededor, con claro paralelismo a un episodio de la vida del propio director ${ }^{21}$. Una enfermedad que convierte al niño protagonista, Juanito (Álvaro Sánchez Prieto), en un ser mimado y caprichoso, en el "rey de la casa", con tres mujeres volcadas en servirle: su abuela, su madre y su tía. Sin meternos a fondo en las distintas historias familiares, podemos destacar dos elementos que aparecen en el filme y que nos interesan como fotografía de la época: el silencio y la hipocresía. Juanito muy lentamente va descubriendo la verdad oculta tras ciertos sentimientos y comportamientos gracias a su capacidad de observación y análisis; va poco a poco "atando cabos": su tía Ana, casada con Óscar, el hijo de la matriarca y dueña de la casa, doña Gloria, está enamorada en realidad de su cuñado, Juan, el hermano pequeño de su marido y vive un matrimonio infeliz aunque aparenta respetabilidad; su padre, del que, desde pequeño, su familia ha justificado su ausencia alegando que ocupa un puesto importante a las órdenes de Franco (y así es como se le reconoce en el hogar), no es sino un simple camarero encargarlo de servirle la comida, algo que sólo se descubre cuando, al pasar la comitiva del Dictador por el pueblo, camino de la inauguración de un pantano, el padre se reúne con el niño; la abuela, doña Gloria, debe su

\footnotetext{
${ }^{20}$ Tenemos la experiencia personal durante nuestros años de docencia de la atracción que para gran parte del alumnado tiene el tema de la historia de la educación en España durante el Franquismo porque era una etapa que para muchos era la gran desconocida y algunos nos informaban que sólo después de trabajarlo en clase y preguntar sobre ciertos temas en casa se han enterado de historias familiares que permanecían en el silencio. Nuestra docencia se ha desarrollado tanto en la Facultad de Ciencias de la Educación de la Universidad de Sevilla, y principalmente en la licenciatura de Pedagogía y en la diplomatura de Magisterio.

${ }^{21}$ Con ocho años, una criada que servía en casa del director le pegó el bacilo de Koch, hecho que lo retuvo en cama una larga temporada. Su cama de enfermo fue instalada en el comedor, para evitar que se aburriera solo en su cuarto, y desde allí iba contemplando las vicisitudes de sus familiares (VICENT, 2016).
} 
holgada posición económica a la práctica del estraperlo, muy habitual en tiempos de escasez. En definitiva, Demonios en el jardín nos presenta el retrato de una España con miseria no sólo económica sino moral.

La muchacha de la bragas de oro, filme dirigido por Vicente Aranda en 1979 y basado en la novela de Juan Marsé del mismo título, ganadora del Premio Planeta de 1978, sitúa la acción en la Transición. Sin embargo, al ser constante la alusión a la inmediata época pasada, al régimen franquista, hemos decidido incluirla dentro de nuestra muestra dada su relevancia respecto a nuestro objeto de estudio. La trama es la siguiente: Luys Forest, viejo escritor falangista, se dedica a escribir sus memorias, en las que continuamente va retocando su pasado para convertir hechos desagradables, incómodos, no convenientes en una época en que la democracia aparece como victoriosa, en algo novelesco, heroico y sobre todo oportuno a la situación actual. Junto a él su sobrina Mariana, "la chica de las bragas de oro", va mecanografiando sus escritos y, al mismo tiempo, va desvelando sin tapujos toda la verdad, revelando al público espectador las miserias, hipocresías, y falsedades del personaje masculino principal ${ }^{22}$. Subrayamos dos ejemplos muy representativos. Al principio del filme, Forest está narrando, en un lenguaje grandilocuente y que lo convierte en héroe trágico, las penurias por las que tuvo que pasar para conseguir sacar a su padre, de ideología republicana, de la cárcel. Una vez fuera, según relata, es su mismo progenitor el que parece que se deja extinguir hasta que muere y su hermana recuerda ante el mismo ataúd su defensa de los principios democráticos, con un grito cargado de angustia: “!Viva la República!” Es en ese momento, según sigue exponiendo Forest, cuando siente una pesada carga de conciencia y decide abandonar su adhesión sin tachas al Movimiento Nacional, a los principios franquistas, y por tanto, el cargo poderoso que ostentaba dentro de los Servicios Provinciales de Propaganda ${ }^{23}$. Toda esta narración se revelará de inmediato absolutamente falsa y llena de

\footnotetext{
${ }^{22}$ La película, y la novela por tanto de Juan Marsé, tiene una potentísima carga de denuncia, puesto que los españoles del momento estaban viendo ante sus propios ojos continuamente como personas afines al régimen dictatorial del general Franco ocupaban cargos relevantes en el nuevo sistema democrático en una especie de "reconversión rápida de ideología" (dicho con ironía). Ya mencionamos anteriormente que el propio Suárez provenía directamente de las filas del Movimiento Nacional y el Rey Juan Carlos I había sido el designado por el propio Franco como su sucesor tras jurar, el 22 de julio de 1969, fidelidad a los principios del Movimiento Nacional y demás Leyes Fundamentales del Estado.

${ }^{23}$ Obsérvese el estilo de narración del propio Forest: "Febrero 1942: A través de personas amigas, desde los Servicios Provinciales de Propaganda, consigo por fin sacar a mi padre de la Cárcel Modelo. Ninguna ayuda, ni siquiera la apasionada dedicación de mi hermana, es capaz de sustraerlo a la voluntad de morir. Procede a su propia extinción sin pronunciar una palabra, sin una mirada de reproche, como si ésta fuera la única respuesta posible a la paz que, tras la derrota, ha sido decretada a su alrededor. Octubre 1942: Muerte de mi padre. Empeoran las relaciones conmigo mismo. Consigno las miradas acusadoras de los pocos amigos que han acudido al entierro. El dolor silencioso de mi hermana y sobre todo ese gesto inesperado [la hermana cuando van a depositar el ataúd en la sepultura grita: “!Visca la República!” y pone un lazo republicano encima del ataúd].
} 
hipocresía siendo su pretensión hacer creer a los potenciales lectores de su autobiografía que, desde muy temprano, él se apartó de la Falange y cuestionó todos los principios y normas que representaba. El propio escritor, hablándole a su perro justo después de exponer dicho relato, le dice: “¿Lo hago, Mao?, ¿Quién va a darse cuenta después de tantos años de una falsedad tan inocente?"; pero el público espectador de la película se enterará de toda la verdad cuando, al final del filme, visita a Luys su cuñada y ella desvela que el padre de Forest murió en la cárcel, y sólo entonces su hijo intervino para que el velatorio se celebrase en el hogar familiar. Un segundo ejemplo lo constituye el hecho de que el protagonista sitúa en la inmediata posguerra su simbólico acto de afeitarse el bigote que se había dejado "a lo Franco", y, sin embargo, su sobrina le recuerda que lo llevó durante muchísimos años más, hasta tal punto que ella, una jovencita de unos diecinueve años, lo recuerda de niña con él. La réplica de Forest, basada en palabras de Valle-Inclán, es muy interesante en relación con nuestro tema (cine-memoria histórica-socialización política), porque le contesta que, aunque no lo hizo, lo pensó infinidad de veces y que, de todas formas, "nada es como es, sino como se recuerda". El recuerdo como creador de realidad pretérita sirviendo a los intereses del presente.

Hay dos películas del año 1984, ambientadas en la dictadura franquista, que, reflejando el ambiente rural, nos dan visiones prácticamente antagónicas de las personas humildes, del pueblo llano, de tal manera que crean al público espectador sensaciones muy distintas: Tasio (1984) y Los santos inocentes (1984). Tasio, ambientada en el País Vasco, describe las andanzas de un personaje real, Anastasio Ochoa Ruiz (Tasio), carbonero y cazador furtivo, que nació en 1916 y murió en 1989. La película no recorre toda su vida, sino que comienza cuando cuenta unos ocho años de edad y termina cuando tiene unos sesenta. Es fundamental en esta película, dado nuestro objetivo de investigación, el mensaje diáfano que transmite: la búsqueda (y conservación) de la libertad es un valor esencial para ser feliz y mantener la dignidad como persona. Si hubiera que describir sintéticamente a Tasio, sin duda lo haríamos con dos palabras: "hombre libre". A diferencia de otros habitantes de su pueblo que emigran a la ciudad en busca de un "mejor trabajo", entendido como más remunerado económicamente que las labores que desempeñan en el municipio de nacimiento, él prefiere (y defiende) quedarse en su lugar de origen y, ante todo, nunca estar a las órdenes de nadie, no convertirse en un asalariado o un jornalero. Es una persona que, siendo humilde, suscita una imagen poderosa de dignidad de la persona, de honradez, de integridad personal. Y además todos esos valores se perciben unidos a un paisaje hermosísimo en el que se recrea el director

Se agudiza hasta lo insoportable el aplazado dolor de mi conciencia. Enumero escrupulosamente las humillaciones que al final de su vida no pude evitar a mi padre". 
constantemente, el de la tierra vasca, que puede verse como señal de identidad de los hombres y mujeres de este espacio que parecen tener (como simboliza Tasio) una clara conciencia de que nunca van a renunciar a su libertad.

Frente esta visión "en positivo" de valores como la libertad, la integridad, la honradez..., representados por un carbonero vasco, aparece una representación contrapuesta del ambiente rural en Los Santos Inocentes, de Mario Camus, basada en la novela del mismo nombre de Miguel Delibes publicada un año antes, en 1981. Localizada en un cortijo de Extremadura, cerca de Zafra, en los años sesenta, narra la vida de una familia de campesinos españoles (liderada por Paco, el Bajo, casado con Régula) que vive subordinada a la clase terrateniente, trabajando, obedeciendo y soportando humillaciones sin queja alguna. Casi podríamos decir que son el extremo opuesto a todo lo simbolizado por Tasio. En el filme, la clase dominante aparece casi sin excepción envuelta en una absoluta crueldad, manteniendo relegados a todos los pobres campesinos a la categoría de animales, de bestias, cuyas vidas, bajo su mentalidad, se estima sólo en la medida de que funcionen como buenos instrumentos para el logro de sus objetivos. Son muchos los ejemplos para refrendar esta idea pero sirvan como muestra los siguientes. Azarías, interpretado por Paco Rabal, es un hermano deficiente de Régula, la mujer del matrimonio campesino protagonista. Este le confiesa que le han despedido del cortijo donde estaba porque era viejo y ella le responde diciéndole que no puede haber sido ésa la causa ya que "viejo se ha hecho allí", puesto que llevaba sesenta y un años trabajando para el dueño. Paco, el marido de Régula, va a hablar del asunto con el capataz de ese cortijo y éste se ratifica en su decisión espetándole: "Lo mío no es un asilo". Ésta no es ni mucho menos la única muestra de inhumanidad. Cuando después de un largo tiempo viviendo casi como bestias, muy lejos de cualquier grupo humano, en el lugar denominado "la Raya", el señor del cortijo "premia" a la familia de Paco permitiéndole vivir en una casa cerca del mismo, el matrimonio campesino se pone muy contento pensando sobre todo en que de esta manera dos de sus hijos, Quirce y Belén, podrán ir a la escuela (otra de sus hijas, "la Niña Chica" está afectada de fuertes deficiencias que le imposibilitan caminar y controlar movimientos; los sonidos que produce son gritos y aullidos). Sin embargo, cuando el capataz ve a Belén, una adolescente, se le despierta el deseo sexual, y, a pesar de los ruegos de los padres, decide llevársela a servir para su casa, imposibilitándole así el poder estudiar. Ahora bien, el personaje más retorcido es el señorito Iván, el hijo del dueño de la finca, quien utiliza a Paco como su perro en el sentido literal de la palabra, pues se encarga de buscar a cuatro patas el rastro de las piezas de caza y de recogerlas cuando el señorito acierta en el blanco. Iván, en una ocasión en que Paco se cae de un árbol mientras le presta servicios en 
una cacería y se rompe una pierna, le obliga a que no guarde reposo, contraviniendo la prescripción médica, porque lo único que le interesa es ser reconocido como el mejor cazador de las batidas, para lo que necesita el "mejor perro", Paco. Ello provocará que el humilde campesino quede cojo para el resto de su vida.

La clase dominante, la de los señoritos y terratenientes, responde pues a anti-valores como los de inhumanidad, egoísmo, autoritarismo, coacción física y psíquica, infidelidad conyugal... a lo que se une una hipocresía moral absoluta, puesto que, teóricamente, profesan la fe católica y aparentan cumplir sus preceptos (celebración en la capilla del cortijo de la Primera Comunión de uno de los hijos de los hacendados). El espectador, de nuevo, recibe el mensaje, sobre todo emocional, de repulsión hacia toda esa casta inútil que merecería no existir o, por lo menos, no disfrutar de ningún privilegio ni prerrogativa. Todo el filme provoca que el público que ve la película sienta simpatía por los humildes y que sufra en sus propias carnes las humillaciones y miserias a las que son sometidos. Y se indigne al percibir que la respuesta de estos seres humanos, a base de una cultura del miedo y de privación de educación, una estrategia ampliamente utilizada de dominación, sea la de sometimiento, la de aguantar con resignación. Constantemente, el lenguaje de los señoritos es de improperios, de insultos, hacia los labriegos a sus órdenes (por ejemplo, el señorito Iván -interpretado por Juan Diego- suele llamar a Paco, “maricón”); sin embargo, la respuesta de Paco o de Régula, matrimonio campesino protagonista, al dueño es: “Aquí estamos para lo que guste mandar”, "A mandar, don Pedro, para eso estamos"...

Creado este ambiente emocional de rechazo hacia el autoritarismo, el egoísmo, la inhumanidad y la hipocresía de los poderosos - ejemplo para muchos de los dirigentes y privilegiados del período franquista-, así como de compasión, de pena y de dolor ante el trato que han sufrido los más débiles en el régimen recién acabado, se abre camino para la esperanza. Esta viene representada por los dos hijos mayores de la familia campesina, Quirce y Belén. Quirce va a visitar a los padres en un permiso del servicio militar y primero se acerca a ver a su hermana, que está trabajando en una fábrica. Belén le confiesa que prefiere la fábrica a su trabajo como sirvienta porque "no quiere pasarse la vida quitando la mierda de los demás", lo que supone un rechazo frontal a un destino servil y un mensaje al espectador de que uno puede plantarse y cambiar las cosas. Por su parte, Quirce, en su visita a sus progenitores, les cuenta que le han ofrecido un trabajo de mecánico y, por lo tanto, va a salir de la miseria en que viven sus padres. El fragmento que contiene el mayor mensaje de esperanza hacia la transformación a un mundo muy distinto y mejor que el anterior lo proporciona el señorito Iván cuando narra a sus amigos el rechazo de Quirce a una propina 
que intentó darle por sus servicios en la caza, al sustituir a su padre ya inútil por su pierna. Reproducimos el fragmento del monólogo de Iván:

\begin{abstract}
!Qué coño quieren los jóvenes de hoy que no están a gusto en ninguna parte! ¡Una guerra les daba yo! Tú dirás, que nunca han vivido como viven hoy. ¿Qué creen que me hizo el muchacho de Paco esta tarde? Al acabar el cacerío, le largo un billete de cien, de veinte duros, ¿no? Y él dice: "No, no, gracias". Y yo: "Te tomas unas copas, hombre". Y él: "No gracias, ya le he dicho". Vamos, que no hubo forma... Yo recuerdo que antes, coño, iqué digo antes! hace cuatro días, su mismo padre, Paco, digo, decía: "Gracias, señorito Iván" o "Por muchas veces, señorito Iván". Otro respeto. Se diría que los jóvenes de hoy les molesta aceptar una jerarquía. Y es lo que yo digo, Ministro, que a lo mejor estoy equivocado, pero el que más y el que menos, todos tenemos que aceptar una jerarquía: unos abajo y otros arriba. Es ley de vida, ¿no? ${ }^{24}$
\end{abstract}

Quirce encarna la llegada de nuevos valores y actitudes: el rechazo a una sociedad jerárquica y la apuesta por otra donde la igualdad basada en la dignidad de la persona sea un valor central. Es el que ya no tiene miedo a decir "no" a ciertos comportamientos paternalistas, propios de los mandamases (no olvidemos el supuesto paternalismo del régimen dictatorial y el papel de Franco como patriarca), y el que ha entendido que la construcción de la nueva sociedad empieza por que el propio individuo transforme viejos hábitos. Tampoco ha de olvidarse que Quirce sí ha podido ir al colegio, con lo cual se refuerza la idea de la unión de educación, cultura y libertad.

\title{
CONCLUSIONES
}

Las películas cinematográficas constituyen un agente de socialización política poderoso ya que gracias a la interacción de los diferentes elementos que confluyen en un filme (guión, interpretación de los personajes, fotografía, música, montaje...) el individuo espectador se ve afectado sobremanera en ese conglomerado de emociones, sentimientos y racionalidad que configura la inteligencia. Muchas de las producciones cinematográficas que se hicieron en la Transición apoyaron la construcción de una cultura política democrática, no sólo las que reflejaban ese momento histórico (GUICHOT-REINA, 2017) sino también las que situaban su acción en el pasado más reciente. a través de la enseñanza de valores, actitudes y comportamientos que se postulaban como óptimos y del rechazo a ciertas conductas y estilos de vida que son presentados como aberrantes y que se vinculaban a regímenes no-democráticos. Frente a lo que se ha llamado "el pacto de silencio" en el terreno

\footnotetext{
${ }^{24}$ Obsérvese cómo el espectador puede apreciar la deformación de los valores: el respeto durante mucho tiempo se ha intencionadamente querido transformar en sumisión y era un respeto basado en el miedo, en el temor al castigo.
} 
político que se realizó en España durante la Transición por los diversos partidos políticos, acuerdo tácito por el que se convino no pedir cuentas por el pasado ni instrumentalizarlo con fines partidistas, en el ámbito cultural casi podemos hablar de un "pacto de memoria", dada la gran cantidad de películas, libros y exposiciones que se hicieron desde el principio de la Transición y que, además, tuvieron un éxito notable (AGUILAR, 2006, p. 281-282).

La mayoría de los filmes analizados suscitan en el público espectador un absoluto desprecio hacia sistemas autoritarios, represores de los derechos civiles, políticos y sociales que han de caracterizar a las democracias. Unos regímenes autoritarios que se sostienen gracias al apoyo del poder económico de los sectores privilegiados $\mathrm{y}$, en el caso español, del poder religioso ("nacionalcatolicismo"). La clase trabajadora -el pueblo llano- queda aplastada e indefensa ante las tropelías e injusticias que son cometidas por dichos regímenes, ejerciéndose sobre ella todo tipo de violencias. En este sentido, las películas examinadas intentan abrir los ojos, afianzar la capacidad de análisis de los espectadores para que, a través de la repulsión ante la visión de tales desmanes, se comprometan a defender el nuevo sistema democrático que aún daba sus primeros pasos en España y que aparece como el remedio frente a los autoritarismos. Hay un mensaje implícito destinado a que la ciudadanía juegue un papel activo en la construcción y defensa del nuevo orden establecido por la Constitución de 1978.

El valor más reivindicado es el de la libertad, que debe ser universal, extendida a todos los ciudadanos. Una libertad que aparece en sus dos vertientes, la negativa, como no injerencia de agentes externos en las ideas y acciones individuales, y la positiva, como autorrealización, como autenticidad, como capacidad del sujeto para construir su propia vida de acuerdo con su forma de entender la felicidad, que aparece en filmes como Tasio o Los santos inocentes, en este último caso a través del nuevo futuro laboral y de las actitudes vitales de los dos hijos mayores del matrimonio protagonista. Un mensaje que, asimismo, es de esperanza en un mañana mejor que el pasado vivido.

En los dos filmes centrados en la fratricida guerra civil, hay un esfuerzo por borrar una visión maniquea, los buenos frente a los malos, y reflejan que en los dos bandos se cometieron atrocidades y tropelías, dependiendo más de los propios individuos que de la ideología en sí misma. Muy importante, como ya destacamos, es el género de la comedia aplicado al tratamiento de dicho conflicto, de una película que alcanzó y continuó logrando altísimos índices de audiencia, La vaquilla. Género que hace hincapié en la fragilidad humana, en las grandes semejanzas proporcionadas por nuestro común elemento corporal, que obtiene placer y felicidad con los mismos estímulos (buenas comidas, disfrute sexual...) y en 
la necesidad de la convivencia pacífica para su logro. La comedia cuenta además con el fundamental poder de exorcizar el miedo mediante la risa que provoca (BERTHIER, 2003).

Para entender qué ocurrió en la Transición española, es imprescindible considerar la fuerza que tuvo el miedo a la repetición del pasado, el terror a desembocar en una nueva guerra fratricida y a volver a vivir los horrores de la represión del régimen franquista y a una posguerra invadida de miseria tanto moral como económica que reflejan tan bien películas como La Colmena o Demonios en el Jardín, y plagada del drama familiar de la separación impuesta de muchos seres queridos por su adhesión a principios ideológicos disidentes (Los días del pasado, El corazón del bosque, El Sur). Una posguerra que retrata hábilmente la historiadora Carme Molinero (2006, p. 236-237):

El mundo de la posguerra estuvo marcado por la represión: por la represión política
y social sobre los vencidos; por la represión cultural sobre los valores y la obra de
los vencidos; pero también sobre todo aquello que los vencidos entendían como
contrario a la España "auténtica". En este terreno, era fundamental aislar a los
vencidos, combatir el modelo de mujer emancipada, imponer las normas nacional
católicas que negaban el "libre albedrío" de los individuos y reforzaba la sociedad
disciplinada que pretendía el nuevo orden en su conjunto. Por otro lado, ese
conjunto de medidas respondía a la vocación totalitaria del régimen, que intentó que
la vida del país y su gente se adaptase a todos los niveles a las normas impuestas
desde el aparato del Estado. El resultado fue una sociedad claustrofóbica que hizo
muy difícil la vida cotidiana.

Paloma Aguilar constata que, tras muerte de Franco, un sector significativo de la sociedad, al margen de los acuerdos implícitos del ámbito político, el mencionado "pacto de silencio" entre ellos, no se atreve a recordar públicamente la cara más cruda, amarga y terrible de la Guerra Civil ni de la dictadura. El miedo a la repetición del pasado se revela como un mecanismo esencial para explicar lo que se hace $y$, fundamentalmente, lo que deja de hacerse respecto al pasado (ausencia de políticas simbólicas hacia las víctimas de la Guerra Civil y de reparación, tanto material como moral, a las del franquismo) durante los primeros años de experiencia democrática (AGUILAR, 2006, p. 299). A este miedo a la reiteración del conflicto civil y/o el retorno de la dictadura, esta historiadora y especialista en ciencias políticas une un segundo factor: un profundo sentimiento de culpa entre los españoles tanto por la brutalidad de la guerra como por la connivencia de una parte importante de los conciudadanos con la régimen dictatorial. En este sentido, la mayoría de la sociedad apoya la decisión de no instrumentalizar políticamente el pasado para evitar lo primero y no impide que los políticos profesionales, "pasen” por encima del franquismo -y de sus víctimas- para no tener que afrontar lo segundo. Ello también explicaría que "las partes más espinosas del pasado sólo han podido ser abordadas a escala nacional con el advenimiento de una nueva 
generación libre de miedos y de sentimientos de culpa" (AGUILAR, 2006, p. 311), refiriéndose a los nacidos tras 1966.

Si bien el miedo pudo servir para que los españoles pusieran todos los medios a su alcance para no caer de nuevo en situaciones extremas que condujeran a la guerra -miedo y repulsión que como se ha puesto al descubierto en nuestro análisis anterior origina la forma en que se presenta el pasado franquista- también por supuesto actuó de elemento paralizante y desmovilizador de una gran parte de la ciudadanía, que aceptó sin demasiados reparos los acuerdos pactados por los políticos profesionales. En este sentido, es revelador el dato aportado por Aguilar de que en los primeros años tras la muerte de Franco, las prioridades de los españoles eran la paz, la estabilidad y el orden, incluso por encima de la justicia, la libertad y la democracia (AGUILAR, 2006, p. 300).

Por último, queremos resaltar que para las nuevas generaciones que no vivieron los años de la posguerra, gran parte de su forma de concebir lo que supuso en España la guerra civil y el franquismo se debe a las producciones cinematográficas, de tal modo que algunas películas se convierten en "lugares de memoria"25. En el caso de los que sí vivieron bajo dicho régimen, su memoria individual rinde cuentas a la "memoria" que ofrecen los filmes del periodo y puede, en ese sentido, señalar matizaciones, contradicciones, desacuerdos. Las nuevas generaciones no cuentan con ese recurso y el cine, como recreador del pasado, juega un papel de primer orden como configurador de lo que significaron épocas pretéritas (memoria colectiva), más aún cuando el público espectador no está demasiado interesado en contrastar los datos que aparecen en el filme con otras fuentes historiográficas.

\section{BIBLIOGRAFÍA}

AGUILAR, P. Memoria y olvido de la guerra civil española. Madrid: Alianza Editorial, 1996. $435 \mathrm{p}$.

. La evocación de la guerra y del franquismo en la política, la cultura y la sociedad españolas. En: JULIÁ, S. (coord.). Memoria de la guerra y del franquismo. Madrid: Taurus, 2006, p. 279-317.

ARDÁNAZ, N. La Transición política española en el cine (1973-1982). Comunicación y Sociedad, 2, p.153-175, 1998.

\footnotetext{
${ }^{25}$ Para nosotros, que teníamos siete años cuando murió Franco, el cine ha sido siempre muy revelador para representarnos cómo transcurrió la vida en el franquismo. El ambiente de posguerra lo identificamos, por ejemplo, con La Colmena.
} 
BERTHIER, N. Ser o no ser Franco. Naturaleza y función de la risa en Espérame en el cielo, Archivos de la Filmoteca, vol. II, nº 43, p. 166-167, 2003.

BOYD, C. P. De la memoria oficial a la memoria histórica: la Guerra Civil y la dictadura en los textos escolares de 1939 al presente. En: JULIÁ, S. (coord.). Memoria de la guerra y del franquismo. Madrid: Taurus, 2006, p. 76-99.

DAMÁSIO, A. En busca de Spinoza. Neurobiología de la emoción y los sentimientos. Barcelona: Crítica, 2005. 336 p.

ESPARZA, J. J. EI libro negro de Carrillo. Madrid: Editorial Libros Libres, 2010. 250 p.

ESTAPÉ, L. Lluiset Serracant, Flor de Otoño, y el travestismo barcelonés, años 20-30, publicado el 23 de marzo de 2016. Disponible en $<$ http://leopoldest.blogspot.com.es/2016/03/1luiset-serracant-flor-de-otono-y-el.html>. Consulta el: 10 de marzo de 2017.

GUICHOT-REINA, V. Socialización política, afectividad y ciudadanía: la cultura política democrática en el cine de la Transición española. Memoria e Historia de la Educación, $\mathrm{n}^{\circ}$ 5, p. 283-322, 2017.

JULIÁ, S. et al. (coords.). Memoria de la Transición, Madrid: Taurus, 1996. 706 p.

LOWEnTHal, D. The Past is a Foreign Country. Cambridge: Cambridge University Press, $1985.516 \mathrm{p}$.

LUMMIS, T. Listening to History. Londres: Hutchinson, 1987. 175 p.

MARTÍN JIMÉNEZ, V. Televisión Española y Transición Democrática. Valladolid: Ediciones Universidad de Valladolid, 2013. 335 p.

MOLINERO, C. ¿Memoria de la represión o memoria del franquismo? En: JULIÁ, S. (coord.). Memoria de la guerra y del franquismo. Madrid: Taurus, 2006, p. 219-246.

MORODO, R. La Transición política. Madrid: Tecnos, 1999. 248 p.

NUSSBAUM, M. C. Emociones políticas. ¿Por qué el amor es importante para la justicia? Barcelona: Paidós, 2014. 555 p.

PREGO, V. Así se hizo la Transición. Barcelona: Plaza \& Janés, 1995. 690 p.

PRENSA RTVE. Historia de nuestro cine bate su récord de audiencia con La vaquilla (6,9\%), 22 de julio de 2016. Disponible en <http://www.rtve.es/rtve/20160722/historianuestro-cine-bate-su-record-audiencia-vaquilla-69/1374732.shtml $>$. Consulta el: 11 de marzo de 2017.

PUELLES, M. de. Educación e ideología en la España Contemporánea. 2. ed. Barcelona: Labor, 1986. 523 p. 
REIA-BAPTISTA, V. Apropiaciones mediáticas con ejemplos de cine europeo. Comunicar: Revista científica iberoamericana de comunicación y educación, vol. XX, nº39, p. 81-90, 2012.

TORRES, A. M. Diccionario Espasa. Cine Español, Madrid: Espasa, 1999. 1055 p.

VICENT, M.: Ya no hay demonios en el jardín, El País, 19 de diciembre de 2016. Disponible en: $\quad<$ http://cultura.elpais.com/cultura/2016/12/18/actualidad/1482090851_598195.html>. Consulta el: 10 de marzo de 2017.

VALERO, T. Historia de España contemporánea vista por el cine. Barcelona: Publicaciones de la Universidad de Barcelona, 2010. 502 p.

VILARÓS, T.M. EI mono del desencanto. Una crítica cultural de la transición española (1973-1993), Madrid: Siglo XXI, 1998. 312 p. 